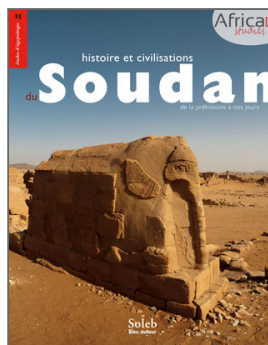

Olivier Cabon (dir.)

Histoire et civilisation du Soudan

De la préhistoire à nos jours

\title{
La religion
}

Odile Nicoloso et Nicolas Beaumé

DOI : 10.4000/books.africae.2982

Éditeur : Africae, Soleb, Bleu autour

Lieu d'édition : Paris, Khartoum

Année d'édition : 2017

Date de mise en ligne : 17 janvier 2022

Collection : Africae Studies

EAN électronique : 9782493207074

\section{OpenEdition}

\section{Books}

http://books.openedition.org

\section{Référence électronique}

NICOLOSO, Odile ; BEAUMÉ, Nicolas. La religion In : Histoire et civilisation du Soudan : De la préhistoire à nos jours [en ligne]. Paris, Khartoum : Africae, 2017 (généré le 28 janvier 2022). Disponible sur Internet <http://books.openedition.org/africae/2982>. ISBN : 9782493207074. DOI : https://doi.org/10.4000/ books.africae. 2982. 


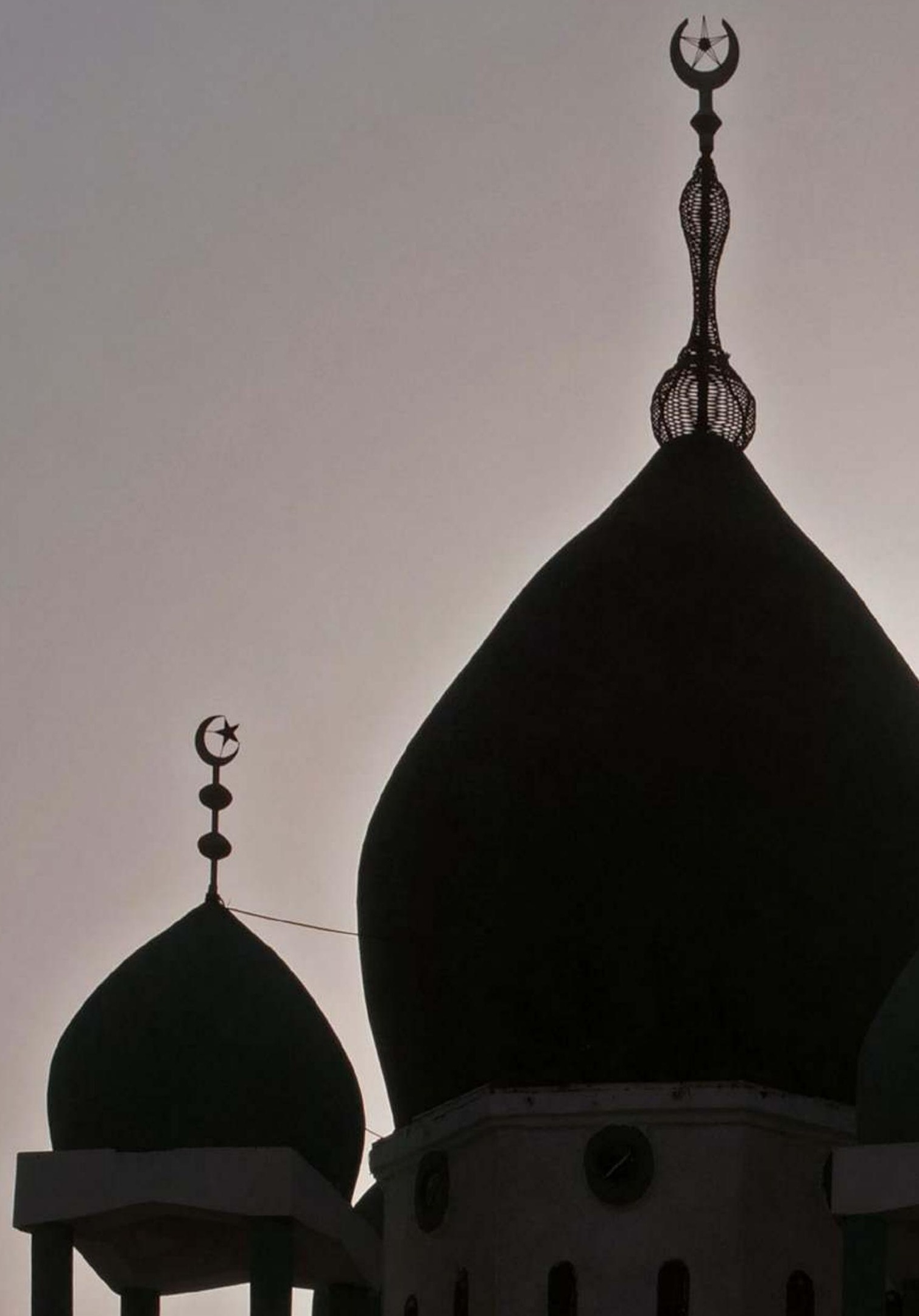


le Soudan

850

aujourd'hui

La plupart des Soudanais sont croyants. Ils sont à $90 \%$ musulmans et à $75 \%$ sunnites. Les autres sont chrétiens ou pratiquants des religions traditionnelles. Les uns et les autres cohabitent dans le respect des droits de chacun. Les mosquées et les églises se côtoient à peu près partout dans le pays.

\section{l'islam}

Les premières attestations de l'islam au Soudan sont de peu postérieures à la mort du prophète Mahomet et coïncident avec la conquête arabe de l'Égypte au vir siècle (639, Amr Ibn al-'As, voir p. 404 sq.), mais il fallut près de neuf siècles et le déclin du christianisme pour qu'il s'étende à l'ensemble du territoire (voir p. 422 sq.). La conversion du Nord Soudan à l'islam s'est faite essentiellement via le soufisme qui professe un lien direct entre Dieu et le croyant grâce à l'ascèse et à la méditation. Le Mahdi, Mohamed Ahmed, ne se considérait pas comme un leader politique mais comme le représentant du prophète Mahomet. Quatre grandes confréries existent au Soudan:

- la Khatmiyya, fondée par Mohamed Osman el-Mirghani, aujourd'hui dotée de son propre parti politique, le Democratic Union Party (Dup);

- la Sammaniyya, la confrérie du Mahdi, liée au parti Oumma;

- la Tijaniya, née en Algérie, principale confrérie du Darfour;

— et enfin la Qadiriyya, la plus importante, dont certains chefs ont pactisé avec le pouvoir.

En 1983, le président Nimeiry, sous l'influence d'Hassan al-Tourabi, promulgua la shari'a. Depuis la deuxième partie du $\mathrm{xx}^{\mathrm{e}}$ siècle, l'islamisme soudanais, inspiré en partie par les Frères musulmans, s'était construit par opposition aux laïcs et à l'islam populaire des confréries soufies, hostiles à l'instrumentalisation politique de la religion.

Le soufisme reste la principale institution sociale dans la société soudanaise, grâce à la créativité de ses responsables, à leur capacité à s'adapter aux défis de la société moderne et aux aspirations de la jeunesse urbaine: il est une clef du maintien de l'ordre social. Au début $\mathrm{du} \mathrm{xx}^{\mathrm{e}}$ siècle, à la suite de l'immigration en Arabie Saoudite, le wahhabisme (politiquement structuré) a fait son apparition. Le salafisme, retour vers un islam pur, influence certains jeunes mais a encore relativement peu d'écho. L'émergence de ces groupes est peut-être due à la politique libérale du régime envers le prosélytisme, une façon pour lui de contrôler la diversité islamique du Soudan. Les incidents qui opposent parfois soufis et sala-

Soufis,

Omdurman, 2012. fistes reflètent la compétition à laquelle se livrent ces tendances religieuses, dans un espace partagé et un contexte de pluralisme religieux. La confrérie soufie se réunit chaque vendredi au cimetière d'Omdurman, sur la tombe 

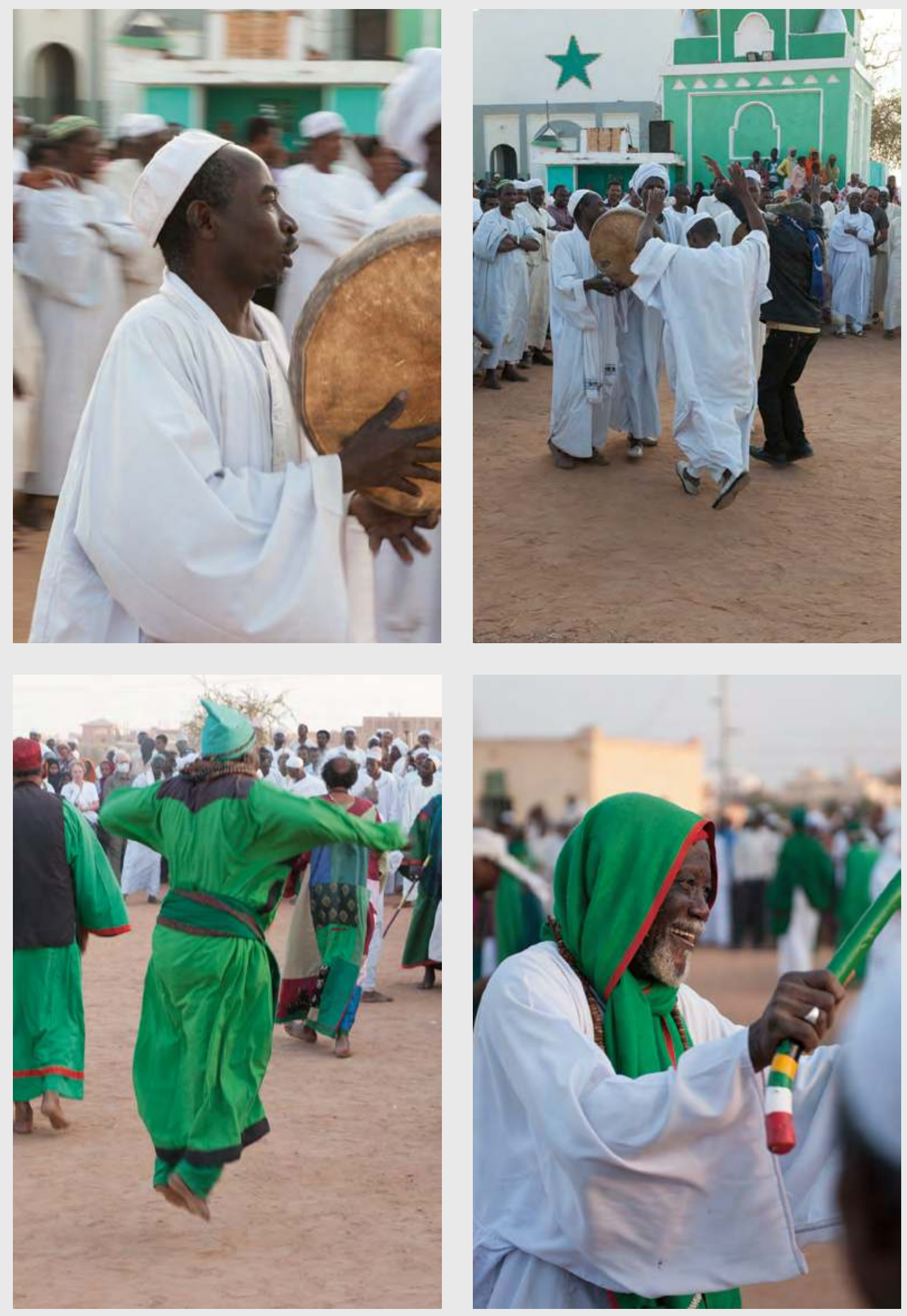
du cheikh Hamed al-Nil. Au son des tambours et des chants, les hommes viennent se balancer longuement d'avant en arrière en répétant la profession de foi musulmane, la chahada. Ils dansent, chantent, et entreprent presque en transes pour se rapprocher de Dieu.

La religion est très présente dans la vie quotidienne. À l'école, on dispense des cours de religion. Ils sont obligatoires et sont ainsi répartis: 1. coran; 2. règles d'hygiène, comportement personnel, sexuel...; 3. législatif — droit des femmes, impôts étatiques, islamiques —; et 4. étude des différentes écoles d'exégèse.

\section{Ramadan au Soudan}

le Soudan

\section{2}

aujourd'hui
Les Soudanais, très religieux, sont tolérants envers les autres religions. Le jeûne du mois de ramadan, suivi par l'ensemble des croyants, est ici plus que partout ailleurs un moment de partage. À Khartoum, au coucher du soleil, sur les trottoirs de la ville, devant les maisons, on dispose des tapis pour accueillir voisins et passants au moment de l'iftar (la rupture du jeûne journalier). Dans la région d'al-Jazira, sur la route qui relie Wad Madani à Khartoum, les villageois arrêtent même les véhicules pour inviter leurs occupants. L'iftar collectif est une tradition ancienne et un devoir religieux que l'on s'honore d'organiser, en dépit des risques d'accident que cela suppose. On sert des plats traditionnels comme l'aber ahmar ou obiod. Cet iftar partagé est un moment de retrouvailles et d'échanges après une année active où famille, amis et voisins n'ont pas toujours eu le temps de se rencontrer. C'est également un moment de partage avec les plus nécessiteux qui crée des liens très importants dans la communauté. Il faut espérer que cette coutume pourra perdurer malgré les difficultés économiques. Pour la fête de rupture du jeûne, la tradition est d'égorger un mouton que la famille élargie partage. Lors du Mouloud, anniversaire de la naissance du Prophète, les derviches, précédés par des cavaliers qui ouvrent la voie, se rassemblent sur la grande place des Califes, à Omdurman, où les confréries soufies dressent leurs tentes et les marchands de sucrerie, dattes ou noix, leurs étals.

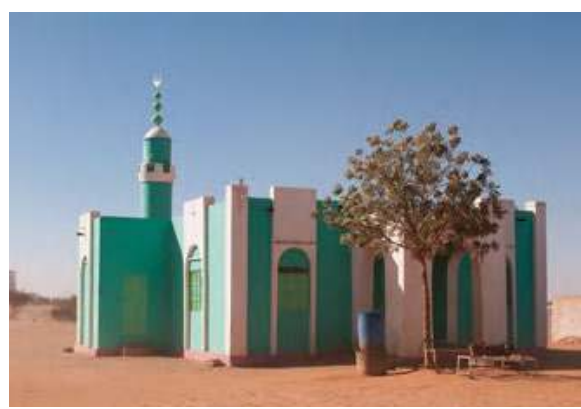

Mosquée attenante

à un « relais routier»,

route de Kourou, 2012. 

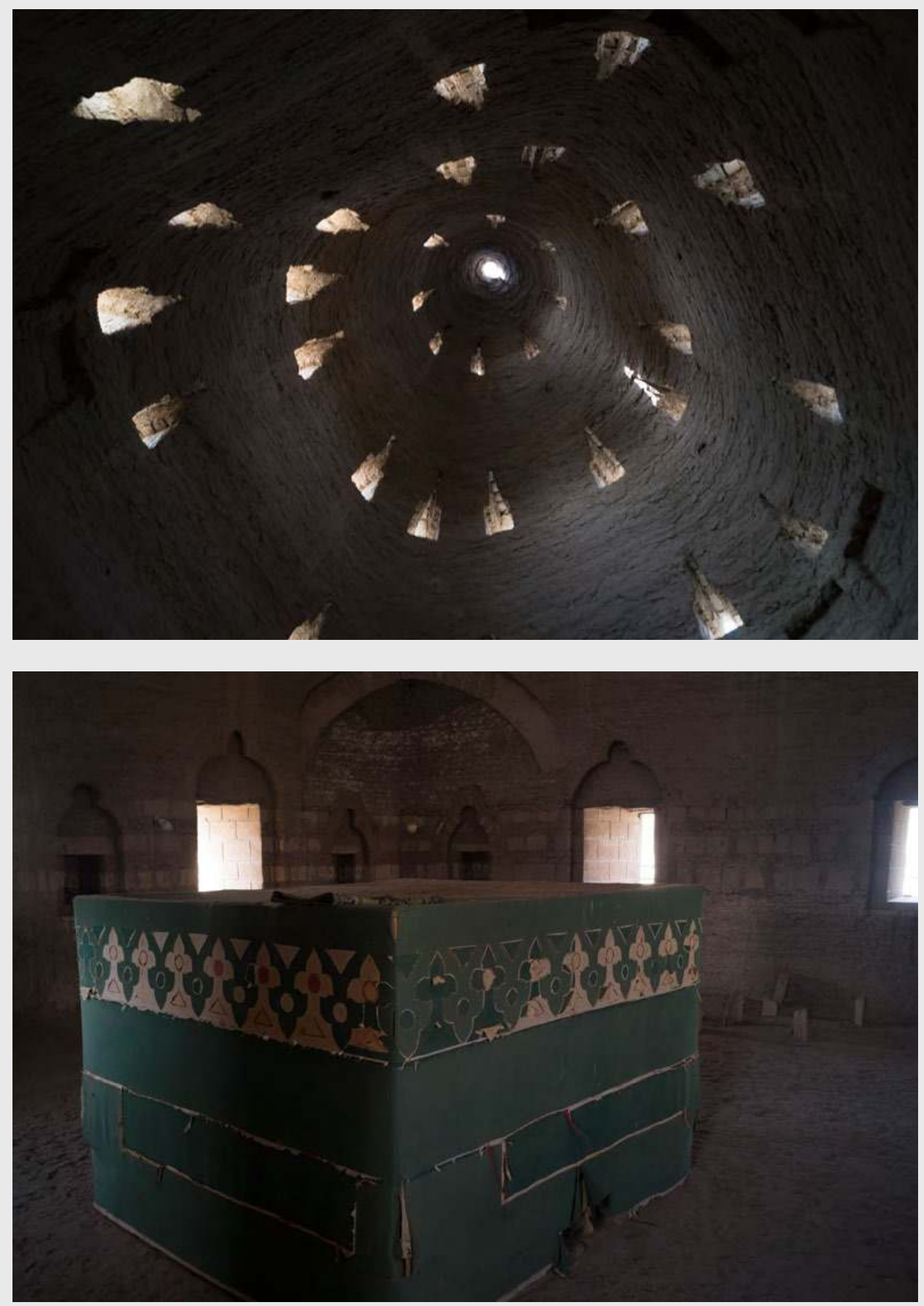


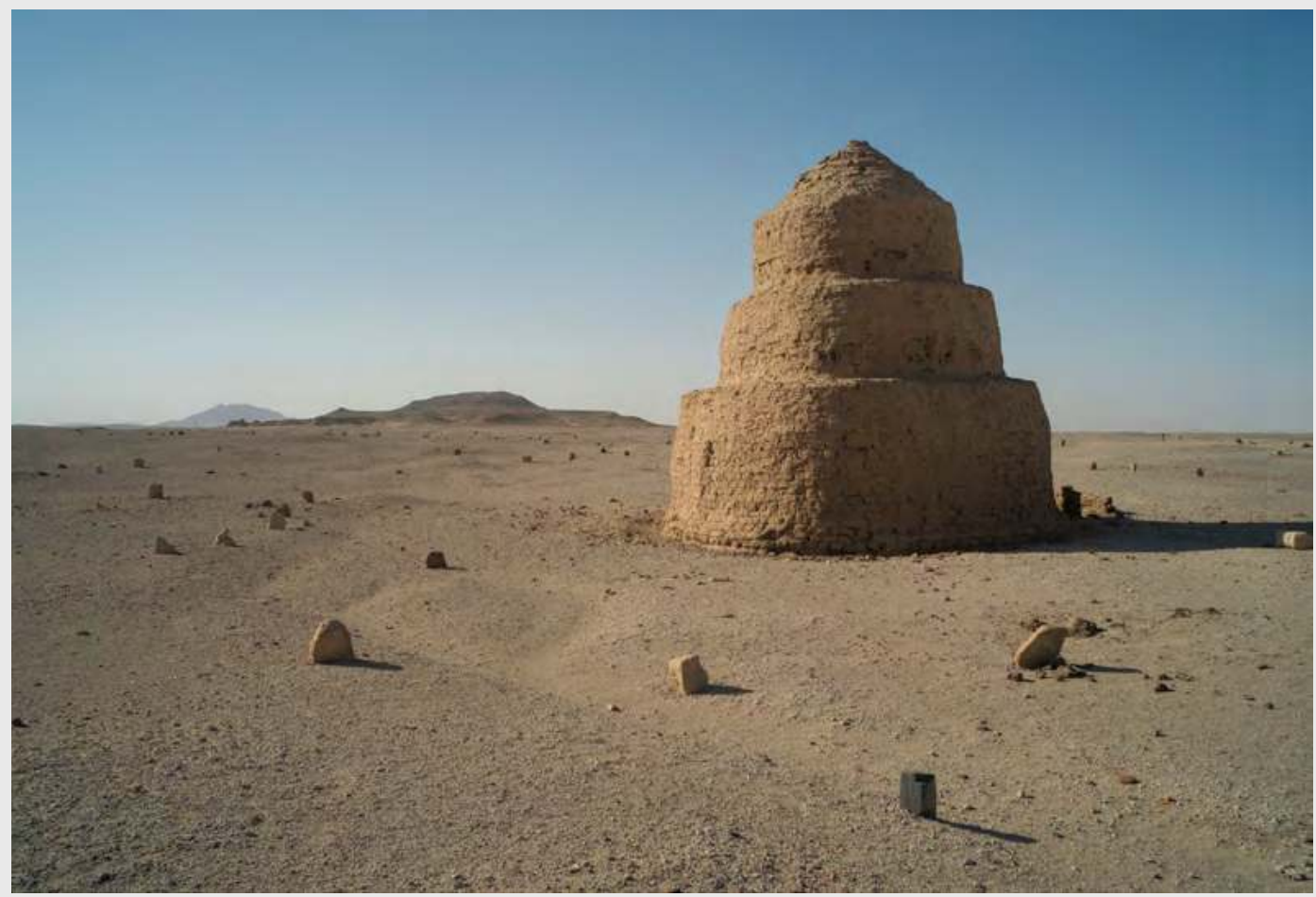

le Soudan

2uba d'un wali («saint homme») dans le cimetière de Saï, 2015.

854

aujourd'hui

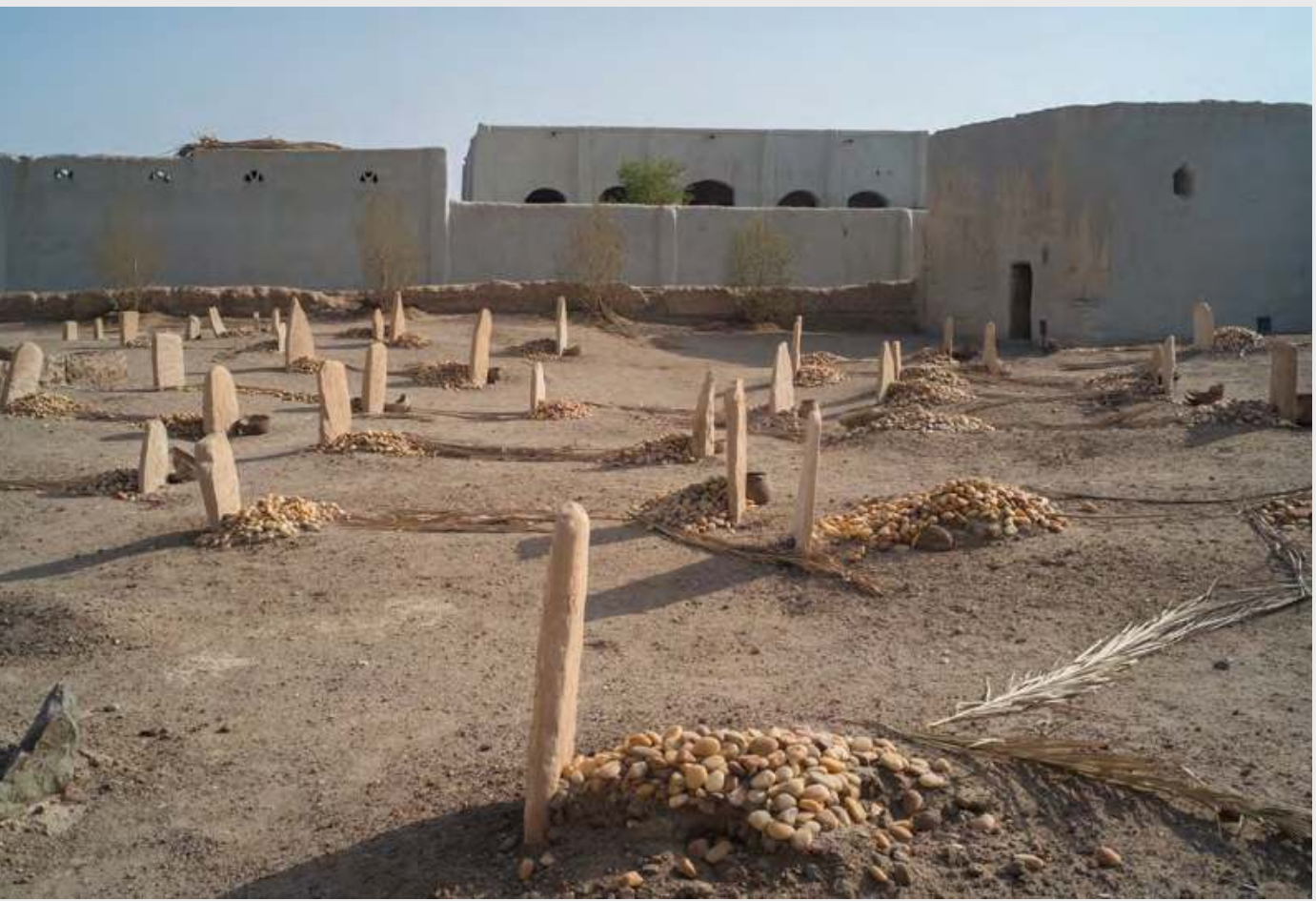

Koya, près de Soleb, cimetière attenant à la kuba du cheikh Idriss, 2015. 


\section{chrétiens et juifs}

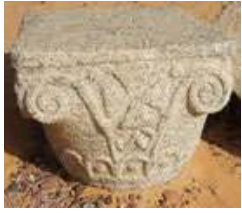

Chapiteau de l'église d'Old Dongola (voir p. 409 sq.).
Peintures de la cathédrale de Faras conservées au musée de Khartoum (voir p. 407 sq.).
Le christianisme est apparu au Soudan à partir du ve siècle (voir p.391 sq.), lorsque des missionnaires venus de Byzance évangélisèrent progressivement le pays. Au milieu du vi ${ }^{\mathrm{e}}$ siècle, trois royaumes chrétiens, dont certains perdureront jusqu'au XVI ${ }^{\mathrm{e}}$ siècle (voir p. 422 sq.), se partagent la vallée du Nil moyen (voir p. 393 sq.). Mais les chrétiens actuels sont les descendants des coptes venus d'Égypte, à l'époque de Méhémet Ali, pour occuper de nombreux postes dans l'administration du condominium anglo-égyptien. Ils parlent arabe, sont complètement intégrés à la société soudanaise et vivent en principe en bonne intelligence avec leurs frères musulmans. Daniel Comboni qui dirigea une mission italienne et créa l'école qui porte son nom fut le premier évêque d'Afrique centrale en 1854. Il mourut à Khartoum et fut canonisé cent ans plus tard.

Les chrétiens - catholiques, protestants, orthodoxes issus de l'immigration levantine (grecs, libanais, syriens) — ont vu leur nombre diminuer considérablement, mais celui-ci est difficile à évaluer, surtout depuis la séparation entre le Soudan et le Soudan du Sud. Avec le départ de la majorité des chrétiens pour le sud et la fermeture de plusieurs églises, ceux qui sont restés, Sudistes ou originaires des monts Noubas, partagent le même sentiment d'inquiétude pour l'avenir. Elle est également nourrie de la crainte que la nouvelle constitution, sous la pression des groupes conservateurs, ne soit rédigée au détriment des droits des non-musulmans.

Les juifs, encore relativement nombreux jusqu'en 1976, comptaient des communautés importantes à Omdurman et à Atbara. Cette année-là, des parchemins religieux précieux sont partis secrètement en Israël.

Un des principaux défis, pour l'État soudanais, est de rassurer et de faire coexister les diverses communautés religieuses de façon à assurer la stabilité et la cohésion sociales
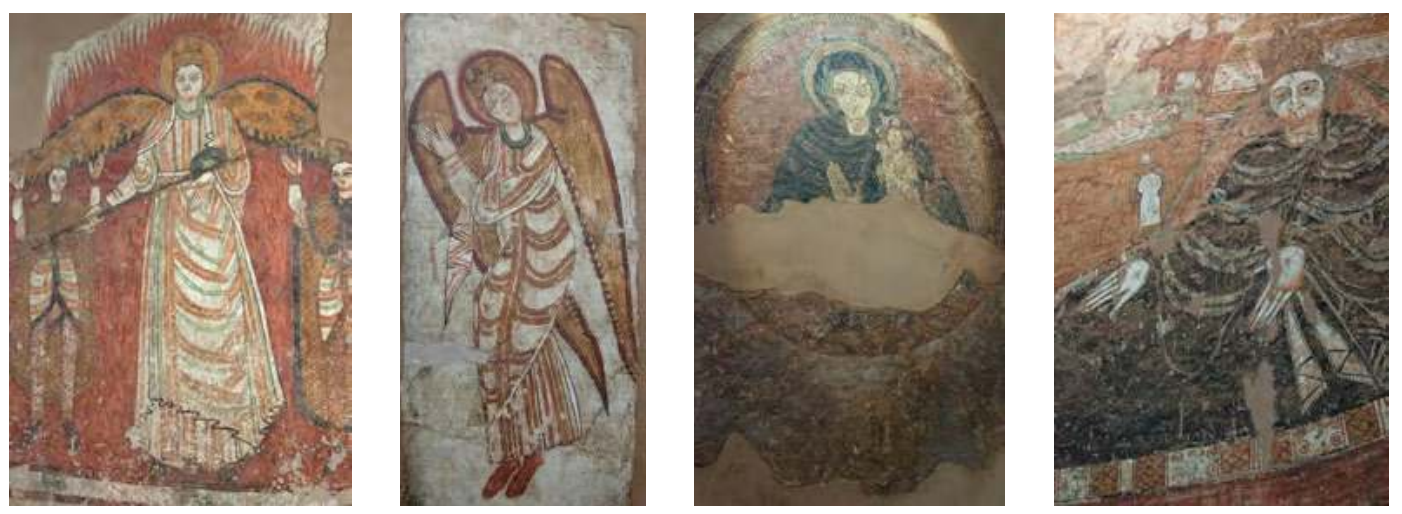